\title{
Simulation and comparison of combined ejector-absorption and single effect absorption refrigeration systems
}

\author{
Nihel Ben Zid ${ }^{1}{ }^{*}$, Mohammed .El Ganaoui², Nejib Hajji ${ }^{1}$ \\ ${ }^{1}$ National Engineering School of Gabes, University of Gabes, 6072 Gabes, Tunisia \\ ${ }^{2}$ Université de Lorraine, Institut Universitaire de Technologie de Longwy, Cosnes \& Romain, (FRANCE)
}

\begin{abstract}
Refrigeration by absorption is gaining more and more importance nowadays especially in applications where the source of energy used in the generator is renewable. However the major problem of this type of refrigeration lies in the COP, which seems to be weaker than compression machines. The use of an ejector is one of the means that can help overcome this problem. In this work, we are interested in the ammonia-water absorption cycle comprising a gas-gas ejector interposed between the generator and the condenser. We suppose that adding a flash tank between the condenser and the evaporator could help improve the entrainment ratio of the ejector. Simulations using the Hysys software are performed in order to look for the optimal conditions for the work of this machine and to make a comparison in terms of performance with single effect cycles. Results showed a significant improvement in the COP and proved therefore that it has better performance than single effect cycles.
\end{abstract}

\section{Introduction}

The artificial production of cold relies mainly on mechanical vapor compression refrigeration machines which have a negative effect on the environment. To overcome this problem we find new ways to achieve energy efficient systems while having a low environmental impact. In this context, the absorption technology for refrigeration is generating great interest due to the fact that the source of energy used in the generator is renewable. This technology uses as working fluids solutions that incorporate natural refrigerants; the most common are $\mathrm{H} 2 \mathrm{O}-\mathrm{LiBr}$ and $\mathrm{NH} 3-\mathrm{H} 2 \mathrm{O}$.

Therefore, several researches are carried out to improve the performances of these machines through combining them, for example, with the technology of the ejectors. Sun [2] studied this cycle working with the $\mathrm{LiBr}-\mathrm{H} 2 \mathrm{O}$ couple, he compared it to that of the singleeffect cycle and he noticed a considerable improvement of the COP. Alexis [3] carried out an analytical study using two simple models to characterize the performances of an ejector system used for air conditioning, Chen [4] examined a combined cycle with R22 / DME-TEG and he showed that there is an improvement in COP compared to the conventional cycle, especially at lower generator temperatures. R. Sirwan [5] studied the improvement of the ejector cycle by adding a vapor-liquid separator after the refrigerant expander and booster. He mentioned that there is a great improvement in the performance of this cycle.

In this work, we are interested in the ammonia-water absorption cycle comprising a gas-gas ejector interposed between the generator and the condenser. We suppose that adding a flash tank between the condenser and the evaporator could help improve the entrainment ratio of the ejector.

\section{Analysis and modelling}

\subsection{Description of absorption systems Single effect}

The absorption machine uses a binary mixture; one fluid is more volatile than the other and constitutes the refrigerant. In this case, ammonia is the refrigerant and water is the absorbent. We describe the operating principle of the absorption machine in the different elements as it is shown in figure 1, [2]:

-Absorber: The vapor produced in the evaporator is absorbed by the refrigerant-poor solution, this absorption is carried out with an increase temperature and while pressure stays almost the same (Absorber pressure $=$ Evaporator pressure)

-Pump: It is used to lead the rich solution from low pressure (BP) to high pressure (HP)

- Exchanger: The rich solution is preheated by the poor solution coming from the generator

-Generator: The rich solution (1) enters the generator where it is heated to the boiling temperature of the refrigerant.

-Condenser: the vapor of the refrigerant produced (2) is discharged to the condenser where it is condensed - Expansion valve: is used to pass the condensed fluid (3) from HP to BP this is accompanied by a cooling of the liquid refrigerant and a partial vaporization. -Evaporator: The remainder of the liquid refrigerant is evaporated in the evaporator usually at constant

* Corresponding author: benzidnihel@gmail.com 
temperature by absorbing a quantity of heat from the cold source.Returning to the cycle of thermal compression, the poor solution produced in the generator is cooled in the exchanger (7-8) then it is expanded (8-9) before going to the absorber and the cycle is repeated. The absorption cycle analysis is based on the following assumptions:

- Pressure drops and heat losses are neglected.

- Expansion is supposed to be isenthalpic

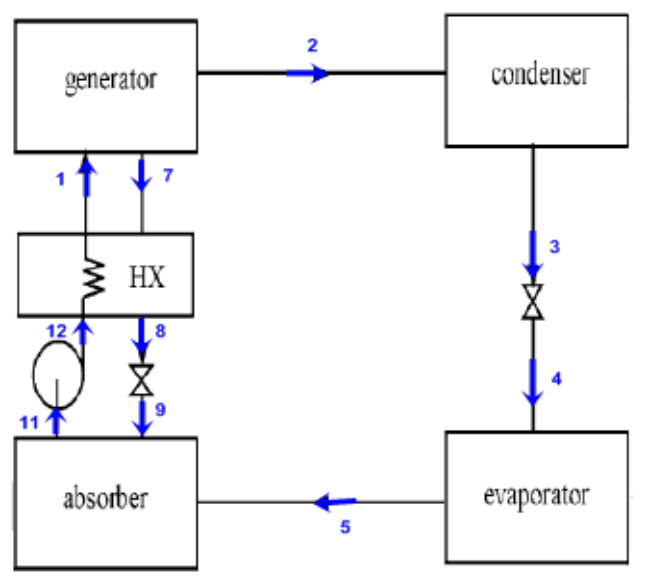

Fig 1: Schematic representation of absorption cycle.

The COP of the cycle can be calculated by the following equation:

$$
C O P=\frac{Q_{e}}{Q_{g}+W_{p}}
$$

With Qev: The heat exchanged in the evaporator Qg: The heat exchanged in the generator Wp: Pump work

\subsection{Oldham diagram}

The refrigeration cycle is shown in the Oldham diagram that is the most used and most convenient for the absorption machine study. As shown in fig.2, the x-axis is scaled in $(1 / \mathrm{T})$ and the $y$-axis in $(\log \mathrm{P})$, on which we can draw the iso-titles of the solution. [5], the straight line with $100 \%$ of concentration corresponds to the vapor-liquid equilibrium of pure ammonia, and the one with $0 \%$ of concentration corresponds to vapor-liquid equilibrium of pure water.

The absorption machine is supposed to function according to the following operating conditions:

Low pressure: $\mathrm{Pe}=327 \mathrm{kPa}$ (the pressure of the evaporator).

-High pressure: $\mathrm{Pc}=1167 \mathrm{kPa}$ (the pressure of the condenser).
-The temperature of the generator $=103^{\circ} \mathrm{C}$.

- The temperature of the absorber $=25^{\circ} \mathrm{C}$.

By fixing evaporation and condensation pressures $(\mathrm{Pe}=327 \mathrm{kPa}, \mathrm{Pc}=1167 \mathrm{kPa})$, the points of intersection with the iso-titration curves corresponding to $99 \%$ of $\mathrm{NH} 3$ represent the evaporator and the condenser then we draw the verticals which can read the corresponding temperatures $\left(\mathrm{Te}=-1^{\circ} \mathrm{C}, \mathrm{Tc}=30^{\circ} \mathrm{C}\right)$ on the diagram . The generator operates at the same pressure as the condenser. Knowing the generator's temperature, in this example it is taken as $103^{\circ} \mathrm{C}$, it proceeds in the same way by raising the vertical up to the intersection with the high pressure Pc. The point of intersection therefore represents the output of the generator. This point belongs to the constant concentration $(x p=0.34)$ where $x p$ is the composition of the poor solution leaving the generator. The absorber operates at the same pressure as the evaporator. By raising the vertical line corresponding to the absorption temperature $\left(\mathrm{Ta}=25^{\circ} \mathrm{C}\right)$, the intersection point obtained thus characterizing the absorber allows to read on the diagram the composition $(\mathrm{xr}=0.52)$ of the rich solution. The intersection of the rich solution line and the isobaric at condenser pressure indicates the threshold temperature (Ts).

The threshold temperature (Ts) is the minimum temperature of the generator, below which the installation does not work, we see that $\left(\mathrm{Ts}=68.14^{\circ} \mathrm{C}\right)$. The Oldham diagram leads to the results shown in Table 1.

Table 1: The values of temperature, pressure and mass fraction during the discharge phase.

\begin{tabular}{|c|c|c|c|c|}
\hline Points & 3 & 5 & 7 & 11 \\
\hline $\mathrm{T}\left({ }^{\circ} \mathrm{C}\right)$ & 30 & -1 & 103 & 25 \\
\hline $\mathrm{P}(\mathrm{kPa})$ & 1167 & 327 & 1167 & 327 \\
\hline $\mathrm{x} \mathrm{NH3}(\%)$ & 100 & 100 & 34 & 52 \\
\hline $\mathrm{x} \mathrm{H2O}(\%)$ & 0 & 0 & 66 & 48 \\
\hline
\end{tabular}

\subsection{Description of ejector-absorption combined systems}

The ejector is a static device based on the effect of Venturi that uses the kinetic energy of a drive fluid, injected under pressure by a convergent or convergentdivergent nozzle into a lower pressure zone, to suck and drive a secondary fluid at low pressure and to compress the mixed flow thus obtained at the desired intermediate pressure. 


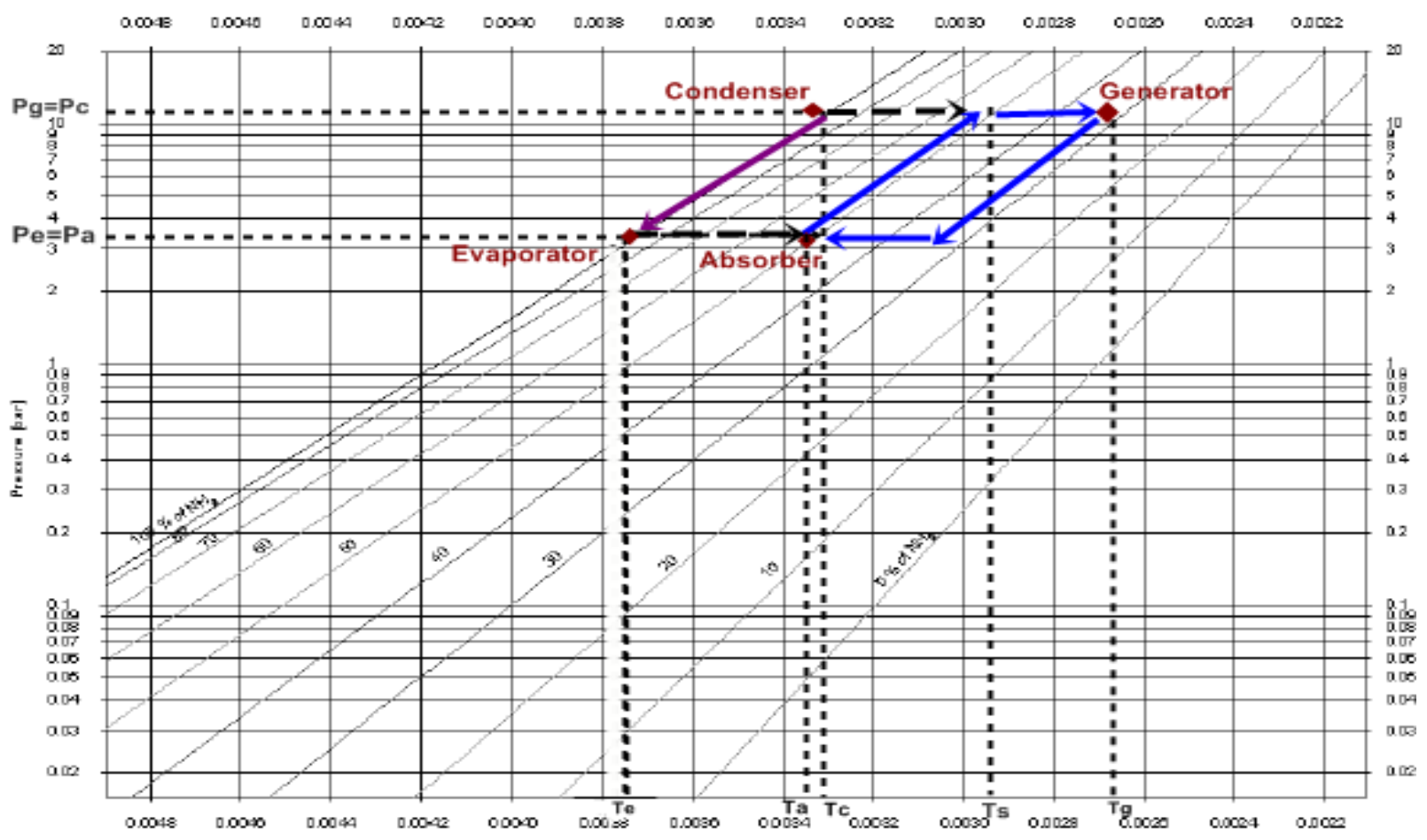

Fig 2: Representation of the refrigeration cycle on the Oldham

In this configuration, the ejector, when placed between the generator and the condenser, will suck up a quantity of vapor of the refrigerant coming from the flash tank. We suppose that adding a flash tank between the condenser and the evaporator could help improve entrainment ratio of the ejector. The combined cycle ejector-absorption is shown in figure 3.

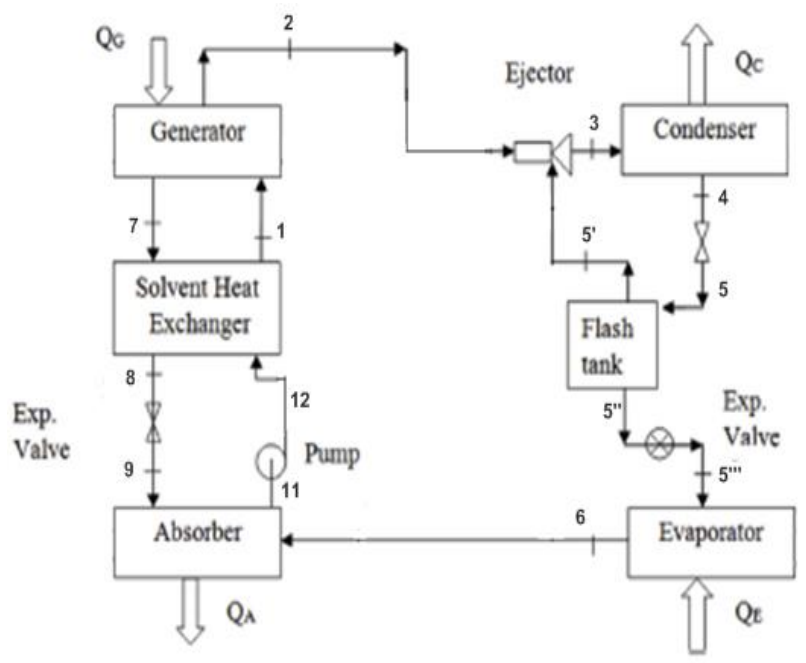

Fig 3: The combined ejector-absorption cycle

\section{Working method}

Our analysis is based on the integral method [6].This method is based on a one-dimensional model of the isentropic flow of ideal gases. It considers the characteristics of the driving and induced fluids at the mixing chamber inlet and the characteristics of the mixture at the mixing chamber exit.
Figure 4 is specifying the notations at the various points of the ejector.

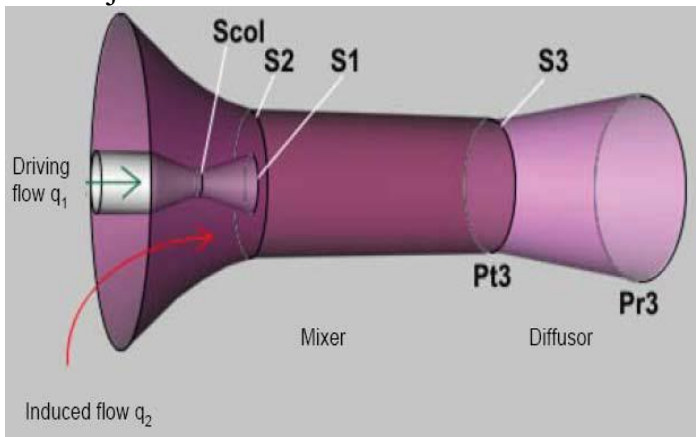

Fig 4: Diagram of the studied ejector specifying the notations at the various points

To determine the outlet pressure Pr3, firstly we specify the pressure $\mathrm{P} 1$ of the motive fluid and $\mathrm{P} 2$ of the induced fluid, the associated total temperatures $\mathrm{T} 1, \mathrm{~T} 2$, the entrainment ratio q2/q1 (driving flow/induced flow), (figure 4).

According to the following equation we can determine the pressure at the exit of the ejector:

$$
\frac{P_{r 3}^{\frac{\gamma_{3}-1}{\gamma_{3}}}-P_{2}^{\frac{\gamma_{2}-1}{\gamma_{2}}}}{P_{1}^{\frac{\gamma_{1}-1}{\gamma_{1}}}-P_{r 3}^{\frac{\gamma_{3}-1}{\gamma_{3}}}}\left(\frac{P_{1}^{\frac{\gamma_{1}-1}{\gamma_{1}}}}{P_{2}^{\frac{\gamma_{2}-1}{\gamma_{2}}}}\right)=f\left(\frac{q_{2}}{q_{1}} \sqrt{\frac{r_{2} T_{2} \gamma_{1}}{r_{1} T_{1} \gamma_{2}}}\right)
$$

After simplifying this equation, we obtain:

$$
P_{r 3}=\left(\frac{P_{1}^{\frac{\gamma_{1}-1}{\gamma_{1}}} \cdot Y+P_{2}^{\frac{\gamma_{2}-1}{\gamma_{2}}} \cdot A}{A+Y}\right)^{\frac{\gamma_{3}}{\gamma_{3}-1}}
$$


The value of $\operatorname{Pr} 3$ is determined using a spreadsheet implemented in HYSYS and based on equations (2) and (3).

\section{Results and discussion}

\subsection{Simulation of absorption systems Single effect}

The work done in this section, is based on the modeling and simulation of the refrigeration machine using the Aspen-Hysys software which is an advanced flowsheeting tool for process simulation. It has a rich library of model calculations of thermodynamic properties.

Figure 5 illustrates the absorption machine model in Aspen-Hysys. The temperatures obtained by the Oldham Diagram $\left(\mathrm{Te}=-1^{\circ} \mathrm{C}, \mathrm{Tc}=30^{\circ} \mathrm{C}\right)$ are used for the simulation of the machine. Stated below in table 2 are the characteristics of the generator's inlet in 1 .

Table 2: Characteristics of the generator's inlet

\begin{tabular}{|c|c|}
\hline Parameters & Values \\
\hline Temperature $\left({ }^{\circ} \mathrm{C}\right)$ & 67.7 \\
\hline Pressure $(\mathrm{kPa})$ & 1167 \\
\hline Mass Flowrate $(\mathrm{kg} / \mathrm{h})$ & 213 \\
\hline X NH3 $(\%)$ & 52 \\
\hline X H20 $(\%)$ & 48 \\
\hline
\end{tabular}

The results of the Aspen-Hysys simulation are shown in Tables 3 and 4. The absorption refrigerating machine works correctly according to the operating parameters presented in the following table.

Table 3: Main simulation results

\begin{tabular}{|c|c|c|c|c|c|}
\hline Stream & 1 & 3 & 5 & 7 & 11 \\
\hline Temperature $\left({ }^{\circ} \mathrm{C}\right)$ & 40.98 & 30 & -1 & 103.6 & 24.6 \\
\hline Pressure(kPa) & 1167 & 1167 & 327 & 1167 & 327 \\
\hline x NH3(\%) & 99.93 & 99.93 & 99.93 & 33.38 & 52 \\
\hline \begin{tabular}{c} 
x H20(\%) \\
\hline $\begin{array}{c}\text { Mass flowrate } \\
(\mathrm{kg} / \mathrm{h})\end{array}$
\end{tabular} & 57.98 & 57.98 & 57.98 & 155 & 224 \\
\hline
\end{tabular}

Upon comparing the pressure and fractions results given by the Oldham diagram and the results obtained using Hysys (Table 3 ), we notice that we get almost the same values of temperature, pressure and composition. This means that the results by Hysys are accurate. Hence, this simulation can be used to study the effect of various operating parameters on the efficiency of the absorption machine.
Table 4: Main Heat loads

\begin{tabular}{|c|c|}
\hline Main Heat loads & VALUES $(\mathrm{kW})$ \\
\hline Qev & 18.19 \\
\hline Qg & 28.16 \\
\hline Wp & 0.08 \\
\hline COP & $\mathbf{0 . 6 4}$ \\
\hline
\end{tabular}

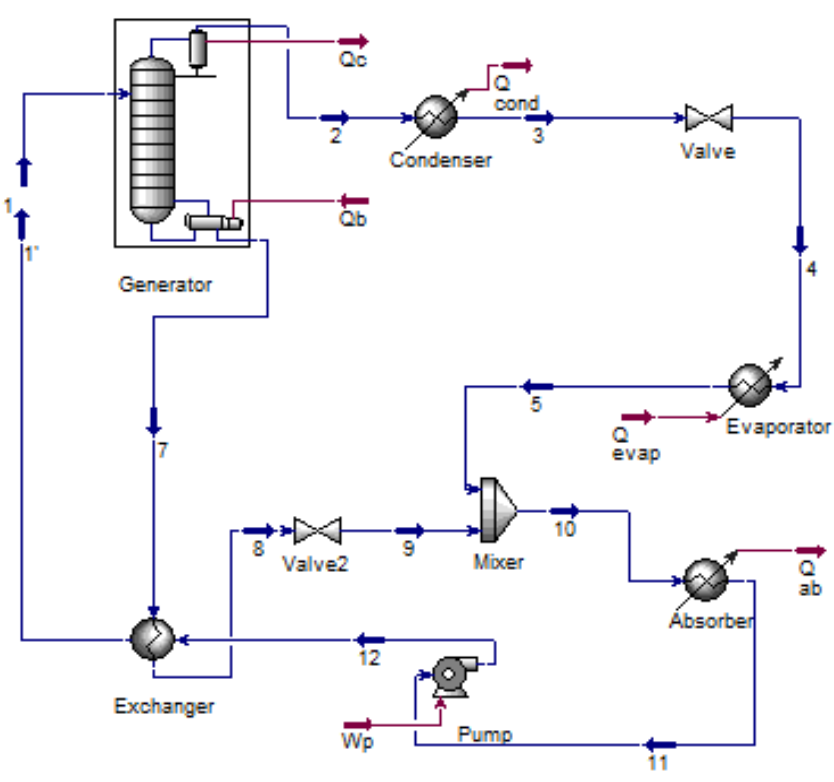

Fig 5: The absorption machine Single effect model in Aspen-Hysys

\subsection{Simulation of ejector-absorption combined systems}

Illustrated in figure 6 is the combined ejector-absorption machine model in Aspen-Hysys. Table 5 shows the ejector parameter given by Hysys.

Table 5: The ejector parameters

\begin{tabular}{|c|c|}
\hline Parameters & values \\
\hline $\mathrm{P}_{1}(\mathrm{kPa})$ & 1167 \\
\hline $\mathrm{P}_{2}(\mathrm{kPa})$ & 680 \\
\hline $\mathrm{Pr}_{3}(\mathrm{kPa})$ & 1130 \\
\hline $\mathrm{T}_{1}\left({ }^{\circ} \mathrm{C}\right)$ & 40.98 \\
\hline $\mathrm{T}_{2}\left({ }^{\circ} \mathrm{C}\right)$ & 12.96 \\
\hline $\mathrm{T}_{3}\left({ }^{\circ} \mathrm{C}\right)$ & 29.28 \\
\hline $\mathrm{q}_{1}(\mathrm{~kg} / \mathrm{h})$ & 57.98 \\
\hline $\mathrm{q}_{2}(\mathrm{~kg} / \mathrm{h})$ & 3.55 \\
\hline $\mathrm{q}_{3}(\mathrm{~kg} / \mathrm{h})$ & 61.53 \\
\hline
\end{tabular}




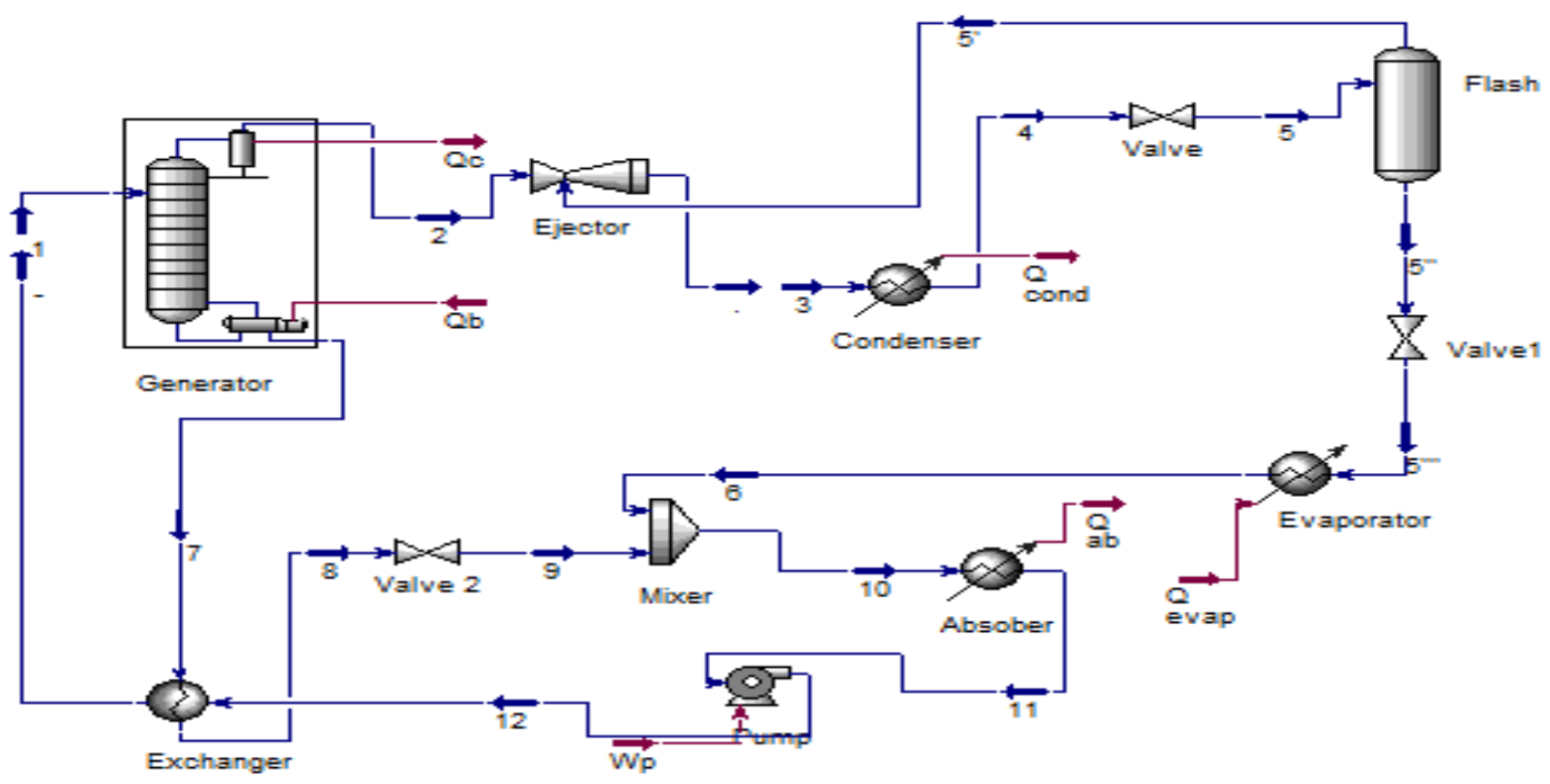

Fig 6: The model in Hysys

The results of the Aspen-Hysys simulation for the main components of this cycle are shown in Tables 6 and 7.

Table 6: Simulation results

\begin{tabular}{|c|c|c|c|c|c|c|}
\hline Parameters & $\mathbf{1}$ & $\mathbf{2}$ & $\mathbf{4}$ & $\mathbf{6}$ & $\mathbf{7}$ & $\mathbf{1 1}$ \\
\hline $\begin{array}{c}\text { Temperature } \\
\left({ }^{\circ} \mathrm{C}\right)\end{array}$ & 67.7 & 40.98 & 25 & -1 & 103 & 24.4 \\
\hline Pressure(kPa) & 1167 & 1167 & 1130 & 327 & 1167 & 327 \\
\hline X NH3(\%) & 52 & 99.93 & 99.93 & 99.94 & 33.4 & 58 \\
\hline $\begin{array}{c}\text { X H2O (\%) } \\
\text { (\%) }\end{array}$ & 48 & 0.07 & 0.07 & 0.06 & 66.6 & 42 \\
\hline $\begin{array}{c}\text { Mass } \\
\text { flowrate } \\
(\mathrm{kg} / \mathrm{h})\end{array}$ & 214.9 & 58.04 & 61.53 & 58.63 & 156.9 & 214.9 \\
\hline
\end{tabular}

Table 7: Main Heat loads

\begin{tabular}{|c|c|}
\hline Main Heat loads & VALUES $(\mathrm{kW})$ \\
\hline Qev & 19.63 \\
\hline Qg & 25.8 \\
\hline Wp & 0.09 \\
\hline COP & 0.76 \\
\hline
\end{tabular}

The results of the simulation obtained by the present study, show that the use of an ejector increased the COP by up to $76 \%$.

$>$ Combining the ejector-flash tank with the single stage absorption cycle using $\mathrm{NH} 3 / \mathrm{H} 2 \mathrm{O}$ as the working fluid has shown considerable improvement in the COP.

\section{Conclusions}

This paper describes a refrigeration cycle using a gas-gas ejector to improve the performance of the absorption machine. A HYSYS simulation was conducted for the two different cycles and used to determine the performance of each system using NH3- H2O. This was shown an increase of the cooling capacity and the combined cycle provides potentially a COP of around of $76 \%$ higher than that of the single effect absorption cycle $(\mathrm{COP}=64 \%)$.

\section{Keywords}

Refrigeration system, absorption machine, combined cycle, ammonia/water, simulation, COP.

\section{References}

1. Sun, D. W., Eames, I. W., \& Aphornratana, S. (1996). Evaluation of a novel combined ejectorabsorption refrigeration cycle-I: computer simulation. International Journal of Refrigeration, 19(3), 172-180.

2. Alexis, G. K., \& Rogdakis, E. D. (2002).Performance characteristics of two combined ejector- absorption cycles. Applied thermal engineering, 22(1), 97-106.

3. Chen LT. A new ejector-absorber cycle to improve the COP of an absorption refrigeration system. Appl Energy 1998;30:37-41.

4. Sirwan, R., Alghoul, M. A., Sopian, K., \& Ali, Y.(2013). Thermodynamic analysis of an ejectorflash tank-absorption cooling system. Applied Thermal Engineering, 58(1), 85-97.

5. Srikhirin, P., Aphornratana, S., \& Chungpaibulpatana, S. (2001). A review of absorption refrigeration technologies. Renewable and sustainable energy reviews, 5(4), 343-372.

6. Antonio, Y. M., Périlhon, C., Descombes, G., \& Chacoux, C. (2012). Thermodynamic modelling of an ejector with compressible flow by a onedimensional approach. Entropy, 14(4), 599-613. 